\title{
Correlated Transcriptional Responses Provide Insights into the Synergy Mechanisms of the Furazolidone, Vancomycin, and Sodium Deoxycholate Triple Combination in Escherichia coli
}

\author{
(D) Catrina Olivera, ${ }^{\text {a* (D) Murray P. Cox, }}{ }^{\text {a (D) Gareth J. Rowlands, }}{ }^{\text {a }}$ (D) Jasna Rakonjac ${ }^{a}$ \\ aSchool of Fundamental Sciences, Massey University, Palmerston North, New Zealand
}

\begin{abstract}
Effective therapeutic options are urgently needed to tackle antibiotic resistance. Furazolidone (FZ), vancomycin (VAN), and sodium deoxycholate (DOC) show promise as their combination can synergistically inhibit the growth of, and kill, multidrug-resistant Gram-negative bacteria that are classified as critical priority by the World Health Organization. Here, we investigated the mechanisms of action and synergy of this drug combination using a transcriptomics approach in the model bacterium Escherichia coli. We show that FZ and DOC elicit highly similar gene perturbations indicative of iron starvation, decreased respiration and metabolism, and translational stress. In contrast, VAN induced envelope stress responses, in agreement with its known role in peptidoglycan synthesis inhibition. FZ induces the SOS response consistent with its DNA-damaging effects, but we demonstrate that using FZ in combination with the other two compounds enables lower dosages and largely mitigates its mutagenic effects. Based on the gene expression changes identified, we propose a synergy mechanism where the combined effects of FZ, VAN, and DOC amplify damage to Gram-negative bacteria while simultaneously suppressing antibiotic resistance mechanisms.

IMPORTANCE Synergistic antibiotic combinations are a promising alternative strategy for developing effective therapies for multidrug-resistant bacterial infections. The synergistic combination of the existing antibiotics nitrofurans and vancomycin with sodium deoxycholate shows promise in inhibiting and killing multidrug-resistant Gram-negative bacteria. We examined the mechanism of action and synergy of these three antibacterials and proposed a mechanistic basis for their synergy. Our results highlight much-needed mechanistic information necessary to advance this combination as a potential therapy.
\end{abstract}

KEYWORDS Enterobacteriaceae, Escherichia coli, Gram-negative bacteria, antibiotic resistance, antibiotic synergy, bile salts, furazolidone, nitrofuran, sodium deoxycholate, vancomycin

ntimicrobial resistance is one of the biggest public health crises at present. With the traditional discovery and development of new antibiotics unable to keep pace with the emergence of resistance (1), alternative strategies are urgently needed to tackle multidrug-resistant bacteria. One promising approach is combining two or more drugs, especially if they are synergistic or have an enhanced combined effect $(2,3)$. Synergistic combinations can lead to better pathogen clearance, may slow down or prevent resistance development, and can lower the doses needed for each of the components, which in turn can mitigate adverse effects $(3,4)$. Repurposing existing drugs approved for human use can also be a faster way of bringing new therapies into the clinic in comparison to the development of novel antibacterial compounds (5).

Our recent studies have demonstrated the synergistic interaction of the existing antibiotics nitrofurans and vancomycin (VAN) with the secondary bile salt sodium
Citation Olivera C, Cox MP, Rowlands GJ, Rakonjac J. 2021. Correlated transcriptional responses provide insights into the synergy mechanisms of the furazolidone, vancomycin and sodium deoxycholate triple combination in Escherichia coli. mSphere 6:e0627-21. https://doi.org/10.1128/mSphere.00627-21. Editor Patricia A. Bradford, Antimicrobial

Development Specialists, LLC

Copyright $\odot 2021$ Olivera et al. This is an open-access article distributed under the terms of the Creative Commons Attribution 4.0 International license.

Address correspondence to Jasna Rakonjac j.rakonjac@massey.ac.nz.

* Present address: Catrina Olivera, Department of Biology, University of Copenhagen, Copenhagen, Denmark.

Transcriptomics study showing that furazolidone, vancomycin, and sodium deoxycholate synergy against Escherichia coli is achieved by amplifying each other's damaging effects, while suppressing antibiotic resistance mechanisms. @MicroMassey @MasseyUni

Received 11 July 2021

Accepted 25 August 2021

Published 8 September 2021 
deoxycholate (DOC) (6). In terms of efficacy and dose reduction, we have shown that combining these three antibacterials is superior to the previously reported double combination synergy of nitrofuran and DOC (7) or nitrofuran and VAN (8). The triple combination is synergistic against a range of Gram-negative bacteria, including the critical-priority pathogens carbapenem-resistant Enterobacteriaceae and Acinetobacter baumannii $(6,9)$. We have characterized the nitrofuran, VAN, and DOC synergy in vitro, although the mechanism of synergy remains unknown.

Nitrofurans and DOC have variable effects on Gram-negative bacteria, but their exact mechanisms of action are not fully understood. Nitrofurans are prodrugs (10) whose reactive intermediates were reported to damage DNA, induce oxidative stress, and inhibit translation (11-14). On the other hand, the effects of DOC include DNA damage, oxidative stress, protein aggregation, and membrane damage (15-17). In contrast to nitrofuran antibiotic furazolidone (FZ) and DOC, VAN's peptidoglycan synthesis inhibition in Gram-positive bacteria is well characterized (18). However, since VAN is not used in the therapy against Gram-negative bacteria due to high MICs (e.g., >100-fold higher MIC in Escherichia coli than Gram-positive bacteria [6]), its effects on this group of organisms are currently unknown. VAN is a large hydrophilic glycopeptide antibiotic (molecular weight $[\mathrm{MW}]=1,449.3 \mathrm{Da}$ ) and cannot readily diffuse through the outer membrane porins which restrict molecule entry up to $\sim 600 \mathrm{Da}$. Zhou et al. (8) have proposed that small amounts of VAN can nevertheless cross the outer membrane and enter $E$. coli, making it possible for VAN to be synergistic with trimethoprim and the nitrofuran antibiotic nitrofurantoin. Increasing evidence also points to VAN having the same target and mechanism of action in Gram-negative bacteria. For example, low temperature can compromise the outer membrane and sensitize $E$. coli to VAN, and this sensitivity can be reversed by introducing an Enterococcus VAN resistance gene cluster that alters the target of the VAN compound (19). Furthermore, breaching the outer membrane in E. coli by expression of leaky mutant secretin channels lowers the MIC of VAN to as low as that for Gram-positive bacteria, ruling out the possibility that target differences are the reason for the high MIC in Gram-negative bacteria (20).

Gram-negative bacteria are normally inherently resistant to VAN and DOC $(21,22)$, but the enhanced efficacy of the combination provides an opportunity to expand the use of these normally Gram-positive-only antibacterials to Gram-negative bacteria (6). Additionally, the possibility of dose reduction could mitigate nitrofuran's reported mutagenicity $(23,24)$. The triple combination, therefore, shows considerable potential as a viable antibacterial treatment option. Understanding the mechanistic bases of the synergy will help advance this combination into the development pipeline and inform the rational design of superior combinations that include any of these antibacterials. This study examined the mechanisms of action and synergy of the nitrofuran furazolidone (FZ), VAN, and DOC (FVD combination) using a transcriptomics approach in the Gram-negative model bacterium E. coli. We show that the FVD combination mitigates nitrofuran mutagenicity, and by identifying perturbed pathways, we propose mechanisms for the action and synergistic interactions of the FVD combination.

\section{RESULTS}

Extensive transcriptional responses to the FZ, DOC, and VAN combination. We conducted transcriptome sequencing (RNA-Seq) analysis to investigate the transcriptional profile of $E$. coli in response to FZ, VAN, and DOC alone or combination (FVD). To prevent the transcriptome profile from being overwhelmed by stochastic expression of cell death genes and other transcriptomic changes unrelated to the drug perturbations, we applied the treatments at subinhibitory concentrations and short exposure times (i.e., $50 \%$ inhibitory concentration $\left[\mathrm{IC}_{50}\right]$ for $1 \mathrm{~h}$, see Materials and Methods). Clustering samples into distinct groups by principal-component analysis demonstrated high reproducibility across replicates and showed that all treatments, except for VAN, had distinctive effects on the transcriptome profile (see Fig. S1A in the supplemental material). Compared to the no-antibacterial control, we identified $>1,200$ differentially 
A

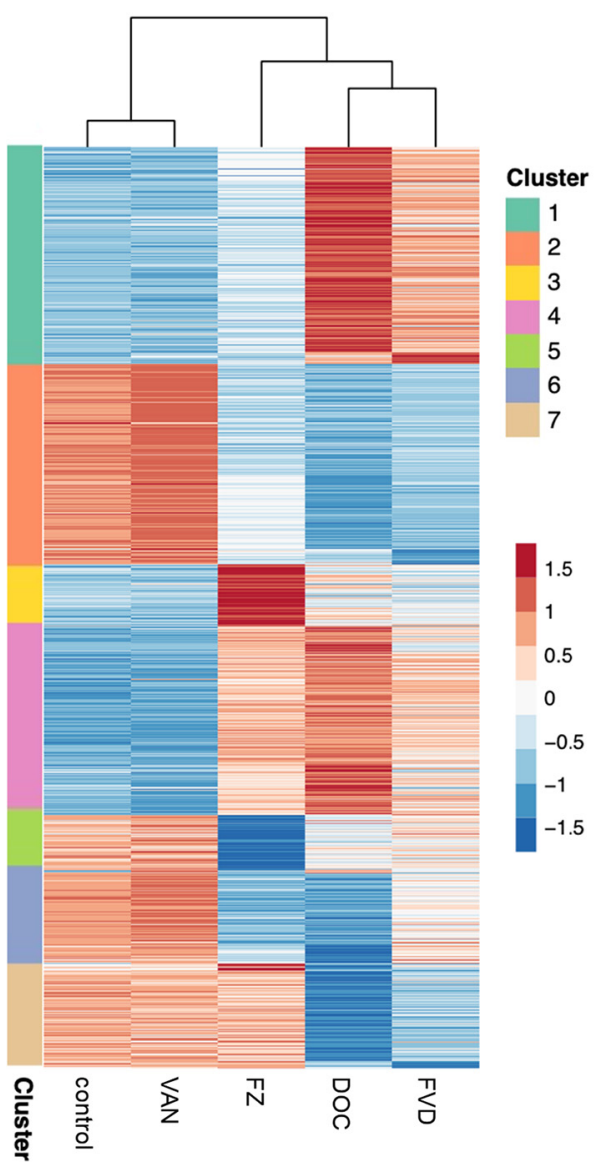

B

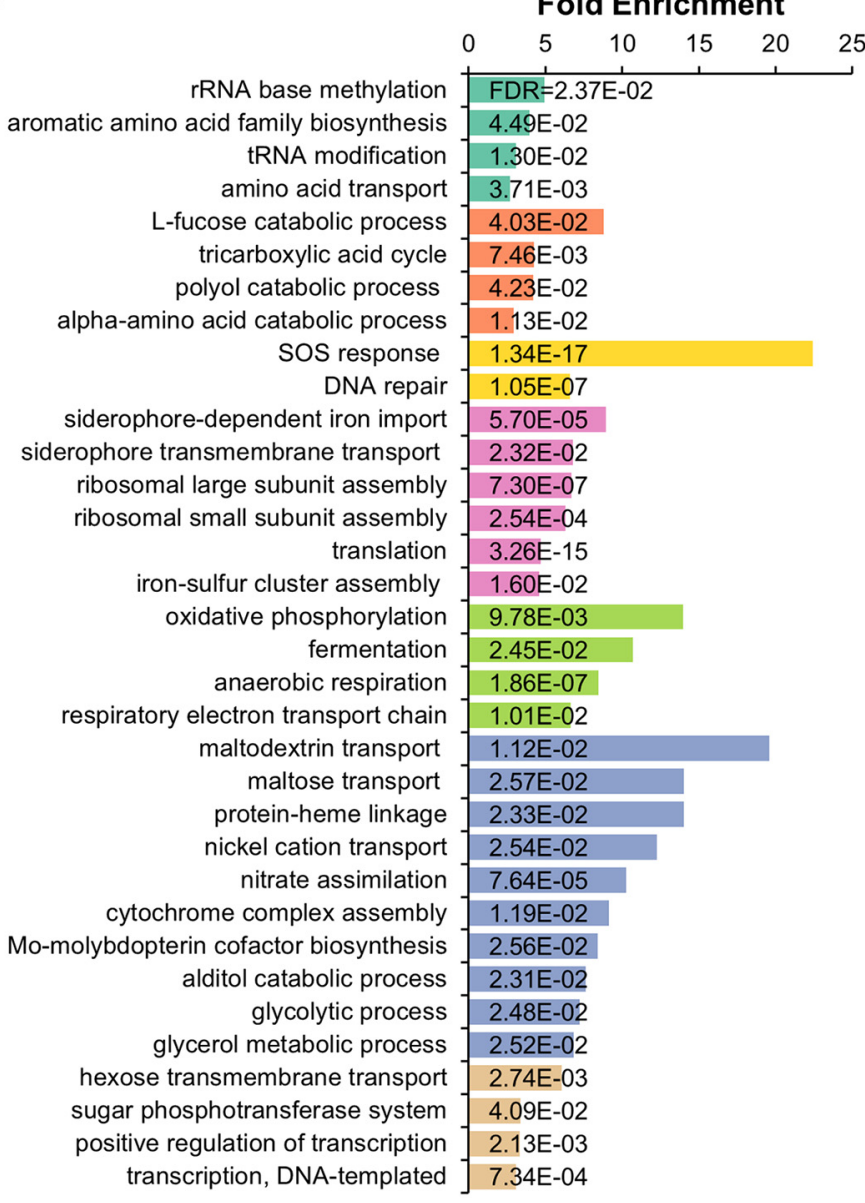

FIG 1 Heatmap of k-means-clustered DEGs and GO term enrichment analysis. (A) Differentially expressed genes clustered into seven groups using k-means. Expression levels displayed were row-scaled regularized log-transformed normalized counts. (B) Each cluster was subjected to a biological process GO overrepresentation test, and the top enriched GO terms for each cluster are shown.

expressed genes (DEGs) in each of the treatments (Data Set S1), except for VAN, which resulted in only 17 DEGs. FVD combination resulted in 95 upregulated and downregulated DEGs not found in the single antibacterials (Fig. S1C), and all of FVD's enriched Gene Ontology (GO) terms overlapped those of FZ and DOC (Data Set S2).

To gain insights and compare the biological processes affected by the single antibacterials and FVD combination, we performed k-means clustering of all the DEGs (Fig. 1A) coupled with GO term enrichment analysis (Fig. 1B) (Data Set S3). The most significantly altered gene clusters in FZ-treated E. coli compared to the control were members of the SOS response (Fig. 1A, cluster 3) and respiration (cluster 5), while those clusters that were most highly altered by DOC were involved in iron import, translation, and amino acid transport and synthesis (Fig. 1A, clusters 1 and 4). Particularly striking was the major overlap of gene perturbations by FZ and DOC and that the FVD combination resulted in the same pattern of gene cluster dysregulation, albeit sometimes less pronounced (i.e., smaller fold change relative to the control). FZ's, DOC's, and FVD's upregulated genes were involved in iron import (Fig. 2A) and ribosome assembly and translation (Fig. 2B), whereas downregulated genes appear in the respiratory/electron transport chain (ETC) (Fig. 2C) and central carbon metabolism (Fig. 2D).

A closer look at the DEGs showed that the expression patterns in response to FZ and DOC indicate an iron starvation response, specifically, the upregulation of iron uptake, siderophore synthesis, Fe-S cluster assembly, and downregulation of iron storage and utilization (e.g., ETC, tricarboxylic acid [TCA] cycle) $(25,26)$. The majority of 
A

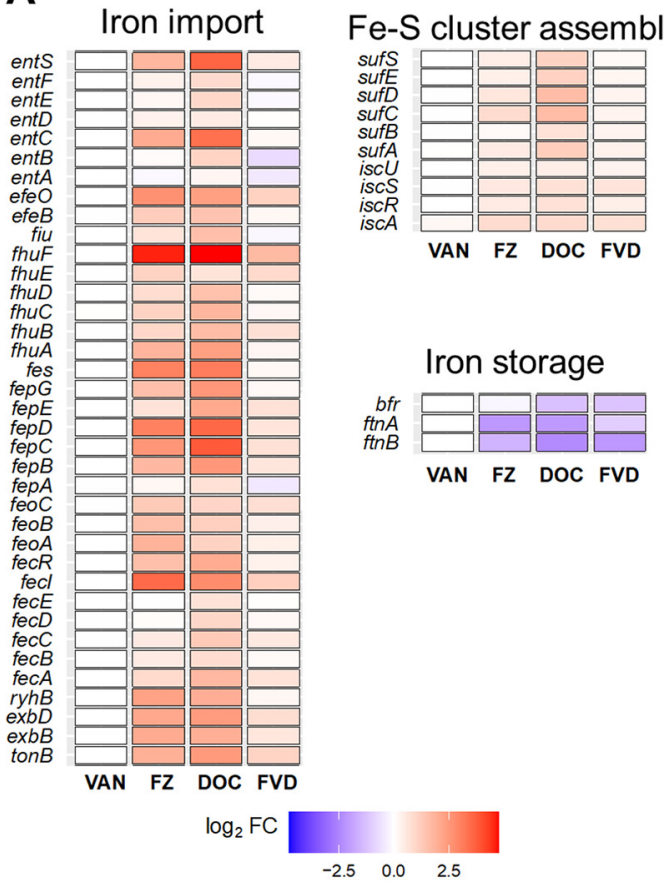

C

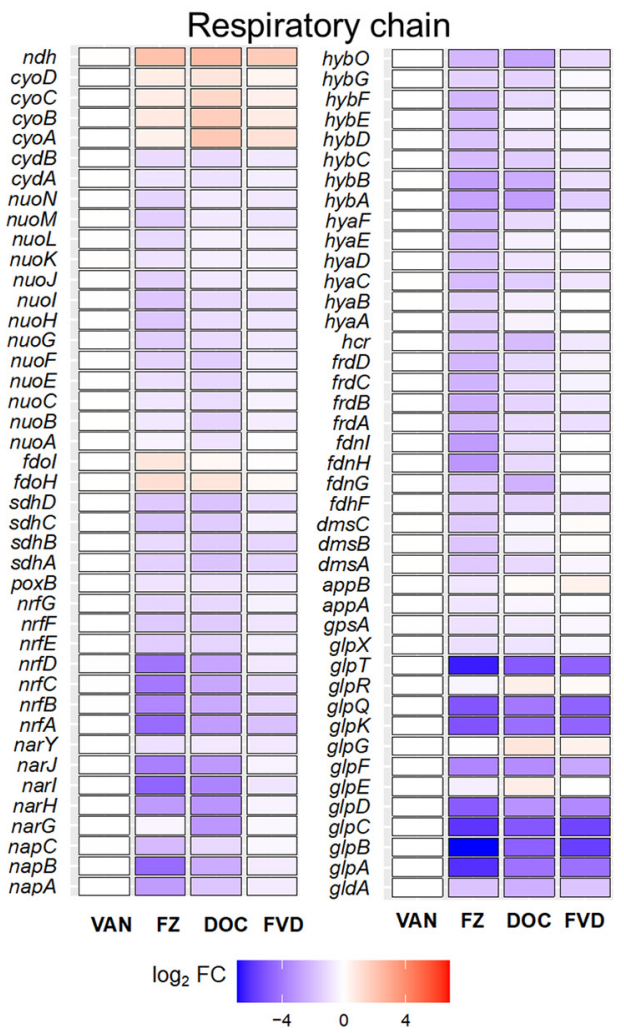

\section{B}
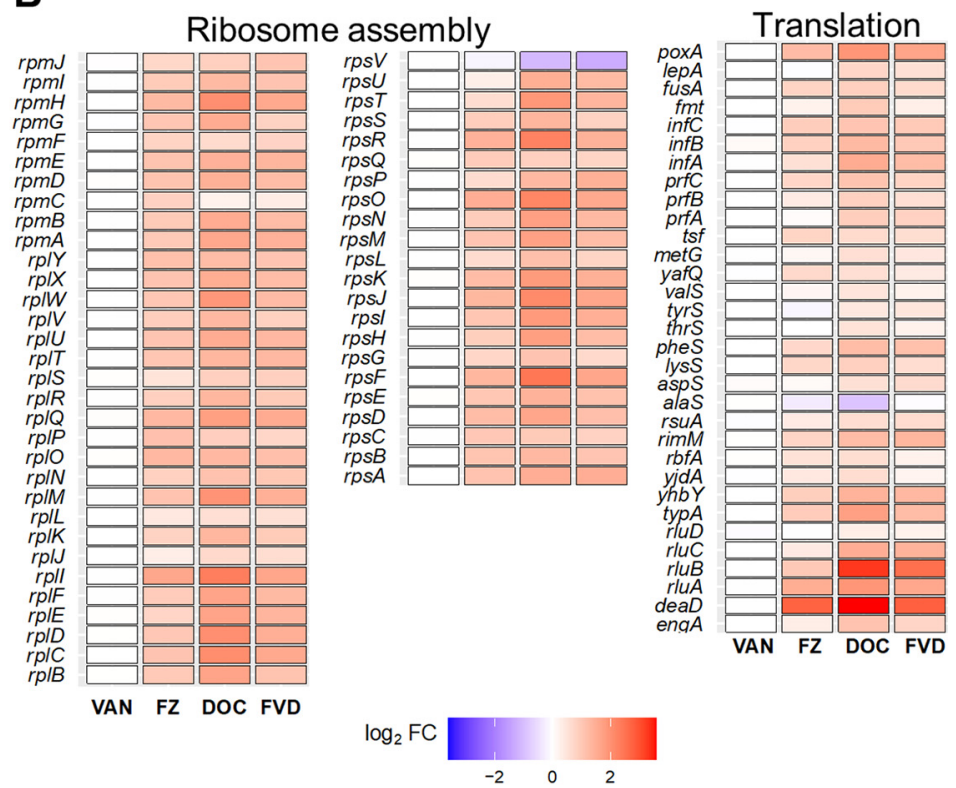

D

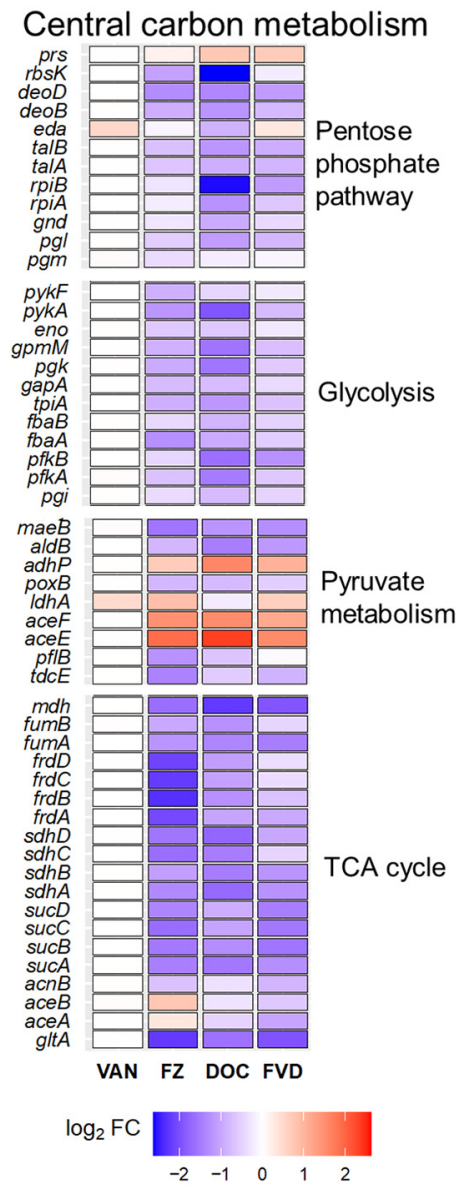

E SOS response

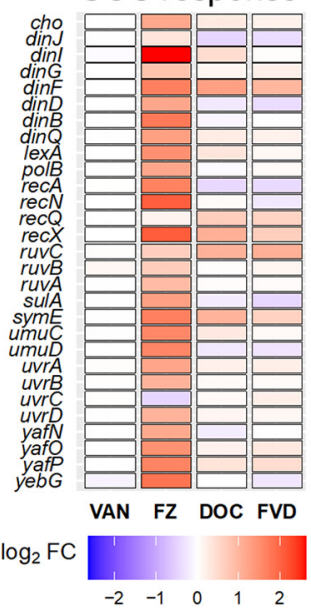

\section{F Other stress}

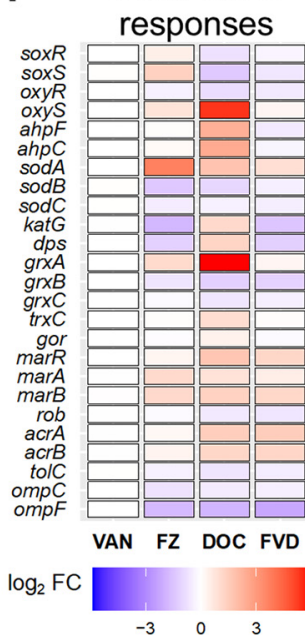

FIG 2 Differential expression of genes in E. coli K1508 treated with FZ, VAN, DOC, or the FVD combination. Expression (log ${ }_{2}$ FC relative to noantibacterial control) of genes involved in iron homeostasis (A), ribosome assembly and translation (B), respiratory chain (C), central carbon metabolism (D), SOS response (E), and oxidative and other antibiotic stress responses (F). 


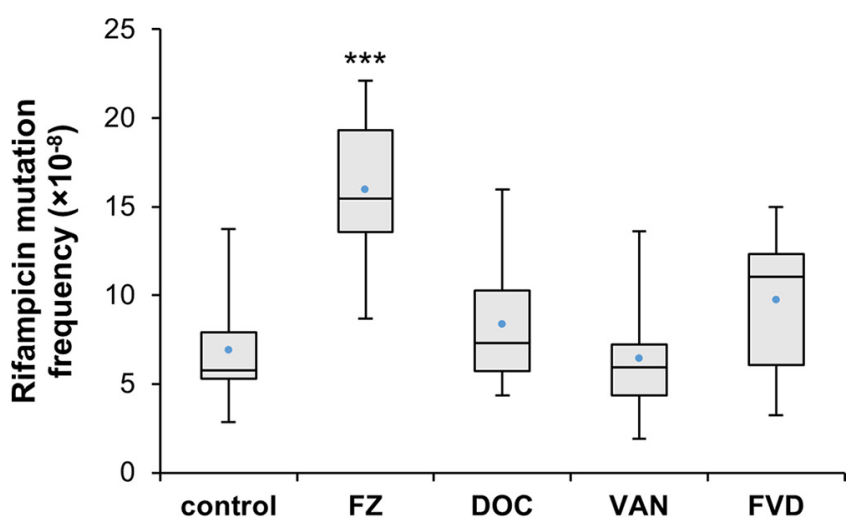

FIG 3 Rifampin resistance mutation frequency in E. coli K1508 treated with FZ, DOC, VAN, or the FVD combination. The mutation frequency of $E$. coli $\mathrm{K} 1508$ cells in the presence of antibacterials was determined by counting the colonies on rifampin $(100 \mu \mathrm{g} / \mathrm{ml})$ plates after $24 \mathrm{~h}$ of incubation. Box plots are derived from 9 to 11 biological replicates. Boxes show the interquartile range, and the whiskers indicate the minimum and maximum values. The mean is indicated by a blue point. Statistical significance (Mann-Whitney $U$ test of treatment versus control) is indicated by asterisks: ${ }^{* * *}$, $P<0.001$.

these genes are either directly or indirectly controlled by the transcriptional repressor Ferric Uptake Regulator (Fur), which is inactivated by iron depletion (27-29). These results therefore suggest that FZ and DOC disturb iron homeostasis by either signaling or triggering an iron starvation response. Other genes induced by $F Z, D O C$, or FVD include oxidative stress genes ( $\operatorname{sod} A$, soxS, $a h p F, \operatorname{ahpC}, \operatorname{gor}, \operatorname{grx} A$ ) and those involved in increased antibiotic tolerance (Fig. $2 \mathrm{~F}$ ). The multiple antibiotic resistance genes marA and $m a r B$, the former of which is a master regulator of a large number of genes involved in resistance, were both upregulated. Similarly, expression patterns for genes that encode efflux pumps and porins are suggestive of the inhibition of entry and accumulation of the antibiotics, such as the upregulation of efflux pump component genes $a c r A$ and $a c r B$ and downregulation of the outer membrane porin genes ompC and ompF (Fig. 2F).

The FVD combination mitigates FZ-induced DNA damage. Genes involved in the SOS response were significantly upregulated in response to $F Z$, while other conditions, including the FVD combination, did not show the same level of SOS response gene upregulation (Fig. 2E), indicating the absence of severe DNA damage. To assess DNA damage levels induced by the antibacterials alone and in combination, we determined mutation frequencies in $E$. coli by quantifying mutant clones that gained resistance to rifampin. Rifampin is an RNA polymerase inhibitor, and resistance can arise through single base substitutions in the RNA polymerase gene rpoB (30). Under nonstress conditions (no-antibacterial control), the spontaneous mutation frequency of $E$. coli K1508 is around 7 mutants per $10^{8}$ cells (Fig. 3). Expectedly, given the DNA-damaging effects of FZ $(11,12)$, this number significantly increased upon FZ treatment (the mean frequency more than doubled). The other two single compounds (DOC and VAN) and the FVD combination, on the other hand, did not result in a significant change in rifampin mutation frequency compared to the control. In comparison to the single antibacterials, the SOS gene induction (Fig. 2E) and rifampin mutation frequency (Fig. 3) by FVD are considerably lower than those by FZ alone and more similar to those by DOC, suggesting that the use of the combination, in which the FZ concentration is lower than when used alone, can mitigate nitrofuran mutagenicity.

FZ and DOC decelerate cellular respiration. Downregulation of genes encoding both aerobic and anaerobic ETC enzymes (Fig. 2C) prompted the assessment of physiological changes at the level of cellular respiration. Since oxygen is the major electron acceptor of the E. coli ETC (31), we investigated the overall effect on respiration by measuring oxygen consumption using a Clark-type oxygen electrode (Fig. 4). Exposure to $\mathrm{IC}_{50} \mathrm{~S}$ of $\mathrm{FZ}, \mathrm{DOC}$, and VAN for $1 \mathrm{~h}$ significantly decreased the oxygen consumption 


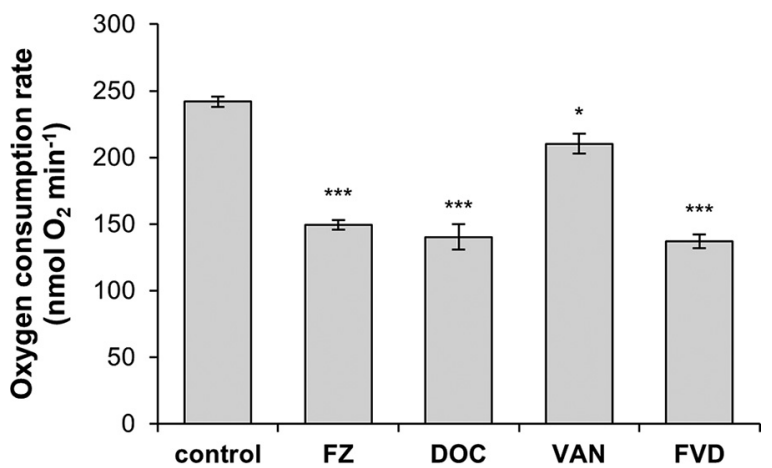

FIG 4 Effect of FZ, DOC, VAN, or the FVD combination on oxygen consumption. Oxygen consumption by E. coli K1508 was measured with a Clark-type closed-chamber oxygen electrode during exposure to $\mathrm{IC}_{50} \mathrm{~S}$ of $\mathrm{FZ}, \mathrm{DOC}$, and VAN alone and in combination. The cells were pretreated with the drugs for $1 \mathrm{~h}$, and then oxygen consumption was measured for up to $5 \mathrm{~min}$. Data show the mean from 3 replicates \pm standard error of the mean. Statistical significance (Student's $t$ test of treatment versus control) is indicated by asterisks as follows: ${ }^{*}, P<0.05 ;{ }^{* * *}, P<0.001$.

rate, causing a 1.6-fold, 1.7-fold, and 1.15-fold decrease, respectively, compared to the no-antibacterial control. Similarly, the FVD combination reduced oxygen consumption by $\sim 1.7$-fold. The pattern of dysregulation of the aerobic ETC genes by FZ, DOC, and FVD potentially reflects an intracellular iron starvation signal (Fig. 2A), which is known to activate iron-sparing mechanisms (28). In this case, the non-iron-utilizing NADH dehydrogenase II (ndh) was possibly upregulated to compensate for the downregulation of iron-rich NADH dehydrogenase I (nuoABCEFGHIJKLMN) (Fig. 2C). In this assay, however, it was shown that the overall effect is a decrease in aerobic respiration.

FZ and DOC dysregulate metal homeostasis. Metal homeostases in bacteria are highly interconnected (32). FZ and DOC dysregulation of genes involved in iron homeostasis prompted us to investigate the intracellular levels of iron and other essential metals (e.g., Mg, Cu, Ni, Zn, and Mn) using inductively coupled plasma mass spectrometry (ICP-MS) analysis (Fig. 5). FZ treatment for $1 \mathrm{~h}$ resulted in a 1.8-fold decrease in iron and a 3-fold increase in manganese levels. On the other hand, DOC resulted in a reduction of magnesium, iron, and manganese and an increase in copper levels. Lastly, the effects of the FVD combination are the same as those of DOC, indicating that DOC drives most of the metal homeostasis changes. However, the fold changes caused by FVD are much more pronounced than those by DOC, reflecting the synergistic effect, such as the 18-fold decrease in magnesium (versus 9-fold by DOC), 2-fold decrease in iron (versus 1.6-fold by DOC), 5-fold decrease in manganese (versus 2-fold by DOC), and 6.5-fold increase in copper (versus 2.5-fold by DOC) (Fig. 5). There was no significant change in the total intracellular zinc and nickel levels with any of the treatments, and VAN did not affect the total intracellular levels of any of the metals analyzed in this study.

The observed changes in metal levels could partly explain the observed transcriptional response to $\mathrm{FZ}$ and DOC. For example, copper excess has been reported to degrade Fe-S clusters, block Fe-S cluster assembly, and stimulate an iron starvation response in E. coli and other bacteria (33-36). Therefore, copper toxicity could be a contributing factor that results in an iron starvation response to DOC or FVD. Similarly, during iron starvation or oxidative stress, manganese import is upregulated to replace iron as a cofactor in essential enzymes or prevent oxidative protein damage $(37,38)$ and could therefore explain manganese levels increased by FZ. Surprisingly, even though DOC induced the expression of oxidative stress genes of the OxyR regulon (e.g., $a h p C, a h p F, k a t G, d p s, g r x A, \operatorname{trx} C$, oxyS) (Fig. 2F), indicating $\mathrm{H}_{2} \mathrm{O}_{2}$ stress (39), it caused a decrease in total intracellular manganese levels. Taken together, FZ and DOC, besides affecting iron homeostasis, also result in the dysregulation of other essential metals, including manganese, magnesium, and copper. 

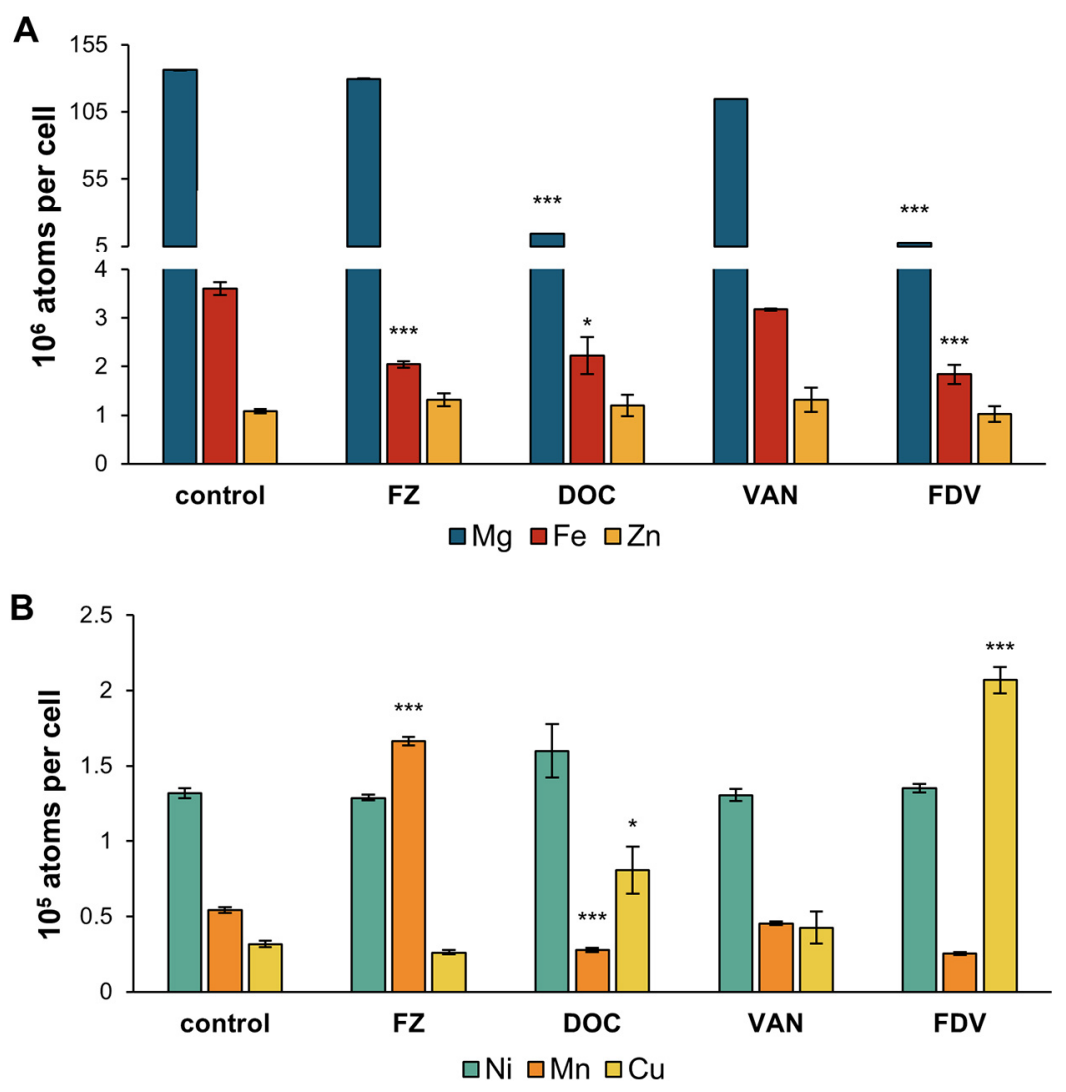

FIG 5 Intracellular metal levels after treatment with FZ, DOC, VAN, or the FVD combination. Due to markedly different cellular concentrations, metals are shown in two graphs: magnesium, iron, and zinc (high levels) (A), and nickel, manganese, and copper (low levels) (B). Total intracellular metal concentrations were measured using ICP-MS in E. coli K1508 exposed to IC I0 doses of FZ, DOC, and VAN alone and the FVD combination for $1 \mathrm{~h}$. Data show the mean from 3 replicates \pm standard error of the mean. Statistical significance (Student's $t$ test of treatment versus control) is indicated by asterisks: ${ }^{*}, P<0.05 ;{ }^{* * *}, P<0.001$.

Possible inhibition of SOS response by VAN. Most of the 17 DEGs triggered by VAN were found to belong to multiple stress response regulons, most frequently those involved in envelope stress: Rcs, Cpx, and Bae (Fig. 6). Upregulation of these genes is consistent with the effects of peptidoglycan synthesis inhibitors that are effective against Gram-negative bacteria $(40,41)$ and supports a VAN mechanism of action identical to that in Gram-positive bacteria (42). Similarly, DOC and FVD upregulated most of the envelope stress genes induced by VAN (Fig. 6). This is not surprising since DOC is known to disrupt biological membranes $(15,17)$. It is possible that membrane disruption by DOC allows more VAN to enter and exert its effect leading to synergy.

To gain more insights into VAN effects on $E$. coli, we analyzed the transcriptomics data from the work of O'Rourke et al. (43), who investigated the transcriptional response of an $E$. coli strain with a compromised outer membrane to various antibiotics, including VAN (43). We performed biological process GO term enrichment of the significantly upregulated and downregulated genes by VAN (i.e., genes with a false-discovery rate [FDR] of $<0.1$ in Data Set S2 from reference 43), but we did not use a fold change cutoff, as in that paper, so as not to omit any information from low-expressed genes. Biological process GO term enrichment of significantly downregulated genes (FDR $<0.01, \log _{2} \mathrm{FC}<0$ ) showed the SOS response to be overrepresented (Fig. S2). The SOS response genes downregulated by VAN in the O'Rourke et al. data set are umuC, umuD, uvrB, uvrC, uvrD, recN, $\operatorname{din} B, \operatorname{din} G, \operatorname{pol} B, \operatorname{cho}$, and sulA. Downregulation of these genes could thus explain the synergy between nitrofuran and VAN reported by Zhou et al. (8), who hypothesized that VAN must increase DNA-damaging effects when combined with DNA-damaging agents, such as nitrofurantoin or trimethoprim. If 


\begin{tabular}{|c|c|c|c|c|c|}
\hline Gene & Regulon & VAN & $\mathbf{F Z}$ & DOC & FVD \\
\hline spy & Cpx, Bae, Rcs & & & & \\
\hline ycfJ & Rcs, Lrp & & & & \\
\hline osmB & Rcs, Nac, $\sigma^{S}$ & & & & \\
\hline yaiY & Lrp, Nac, $\sigma^{E}$, Rcs & & & & \\
\hline$g / y x$ & ND & & & & \\
\hline$b d m$ & Rcs & & & & \\
\hline ypec & Rcs & & & & \\
\hline yaaX & Lrp & & & & \\
\hline ygac & Rcs, Fur & & & & \\
\hline$r \operatorname{cs} A$ & Rcs & & & & \\
\hline$y p f G$ & ND & & & & \\
\hline$h s / J$ & CysB, $\sigma^{E}$ & & & & \\
\hline$y m g D$ & Rcs & & & & \\
\hline ivy & Nac, Rcs, $\sigma^{\mathrm{S}}$ & & & & \\
\hline$c p \times P$ & $\mathrm{Cpx}, \sigma^{\mathrm{S}}$ & & & & \\
\hline$y d h A$ & Rcs & & & & \\
\hline$y m g G$ & Rcs & & & & \\
\hline
\end{tabular}

FIG 6 Differential expression of the 17 VAN DEGs across all treatments. Gene expression differences were presented as $\log _{2} \mathrm{FC}$ relative to no-antibacterial control. Regulators of each gene were derived from information in EcoCyc (https://ecocyc.org), RegulonDB (http://regulondb.ccg.unam.mx), and the literature $(40,76)$; genes with an undetermined regulator are shown as ND. Genes involved in envelope stress are in bold.

VAN exerts the same inhibition of SOS/DNA repair in wild-type $E$. coli, this effect will contribute to the triple synergy by amplifying the DNA-damaging effects of FZ and DOC, in such a way that it decreases DNA damage adaptation and survival through mutagenicity, which increases lethality.

If the SOS response plays a role in the synergy of FVD, for example, through the inhibition of the SOS response by VAN, deletion of recA, which makes $E$. coli unable to mount an SOS response (44), is expected to disrupt the FVD combination's synergy mechanism, therefore decreasing the synergy in the mutant strain. Expectedly, recA deletion increased the susceptibility to FZ by 32 -fold relative to the wild type. Likewise, this deletion also decreased the DOC MIC to $80,000 \mu \mathrm{g} / \mathrm{ml}$ from more than $80,000 \mu \mathrm{g} / \mathrm{ml}$, while the VAN MIC ( $250 \mu \mathrm{g} / \mathrm{ml})$ remained unchanged. In the checkerboard assay to investigate the interaction of FZ, VAN, and DOC, deletion of recA caused a slight increase in the interaction index (fractional inhibitory concentration index $[\mathrm{FICl}]$ ) of FVD ( $\mathrm{FICl}<0.22)$ compared to the wild type $(\mathrm{FICl}<0.13)$, indicating only a slight decrease in synergy (Fig. S3). For the two-drug interactions, only the FZ and VAN combination showed a significant change in the $\mathrm{FICl}$ in the recA mutant (Fig. 7). The deletion of rec $A$ resulted in a shift to indifferent interaction $(\mathrm{FICl}=1)$ instead of the synergy observed in the wild type ( $\mathrm{FICl}<0.38$ ) (Fig. 7A). Taken together, these findings support the hypothesis that the SOS response is an interacting point for the synergy between FZ and VAN. In terms of the triple combination synergy, however, the SOS response contributes to the synergy, but given that deletion of $r e c A$ still results in a synergistic interaction, other factors contributing to synergy are present.

\section{DISCUSSION}

Using a transcriptomics approach, the underlying mechanisms of action and synergy of FZ, VAN, and DOC, and the combination of all three (FVD), were investigated. The apparent similarity in the transcriptional responses induced by FZ and DOC in 

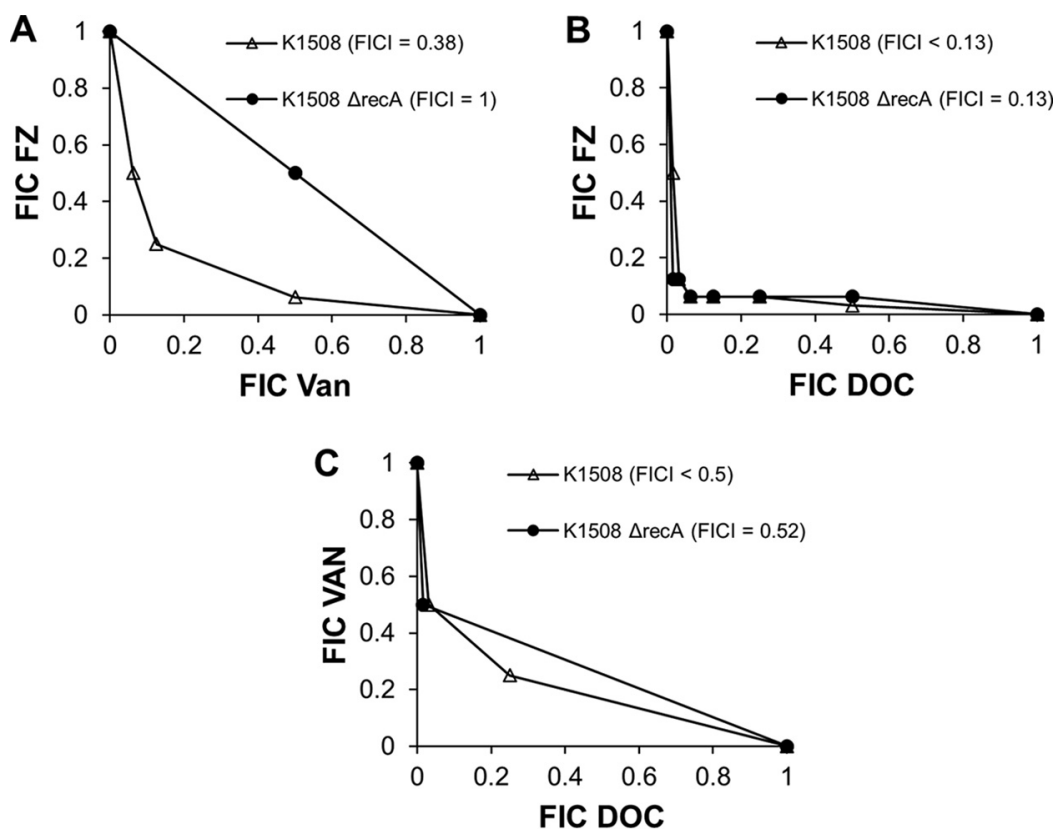

FIG 7 Effect of recA deletion on the two-drug interactions of FZ and VAN (A), FZ and DOC (B), and VAN and DOC (C). Isobolograms were obtained using a checkerboard assay, and each data point represents fractional inhibitory concentrations (FIC; ratio of MICs in combination to those alone).

E. coli is likely the source of their synergy. This is in line with studies that found a higher likelihood of synergy occurring in drug combinations that induce either very similar or opposite gene perturbations $(45,46)$. In particular, FZ and DOC both resulted in the upregulation of genes encoding iron uptake systems and downregulation of those encoding iron storage and iron-utilizing proteins. This response is indicative of Fur inactivation, which usually occurs during iron starvation (29), and is consistent with previous reports of FZ and DOC increasing the expression of iron import genes (47, 48). An E. coli fur mutant grown under iron-rich conditions has been shown to result in a 2-fold iron decrease, while growth under the iron-depleted conditions showed a 14fold reduction (49). Through measurements of the total intracellular iron levels, we determined a less-than-2-fold intracellular iron decrease in the cultures containing FZ and DOC that corresponds to iron-rich conditions, thereby ruling out that these drugs cause real iron starvation.

The mechanisms by which FZ or DOC inactivates Fur and induces an iron-starvation-like response are currently unknown. The mechanism may be as simple as reactive oxygen species oxidizing usable $\mathrm{Fe}^{2+}$ to unusable $\mathrm{Fe}^{3+}$ via the Fenton reaction (50) or damaging the Fe-S clusters (51). If so, iron import would be upregulated to supply iron to the labile iron pool and Fe-S cluster machinery. The Fur-Fe ${ }^{2+}$ complex has also been shown to be inactivated by nitric oxide (52). Incidentally, nitroheterocyclic drug reduction has been proposed to result in nitric oxide by-product (53), though direct evidence for nitric oxide production during nitrofuran activation has not yet been reported. Despite the overall decrease of iron content in the cells, the inactivation of Fur will likely lead to an increase in the labile iron pool inside the cell that can increase oxidative damage and stress via the Fenton reaction (54).

FZ and DOC also caused gene perturbations usually observed in bacteriostatic translation inhibitors, such as downregulation of the central carbon metabolism and respiration, along with the upregulation of ribosomal proteins to compensate for the translational stress $(43,55,56)$. Protein synthesis inhibition by nitrofurans has been reported and was proposed to be due to nonspecific binding to ribosomal proteins and rRNA $(13,14)$. However, translation inhibition by DOC has not been demonstrated previously. Given that the Mg content of the cells is dramatically lowered by DOC, a 
possible connection between $\mathrm{Mg}$ homeostasis dysregulation by DOC and translational stress can be proposed: the decrease in total Mg levels by DOC will decrease the number of functioning ribosomes and thus inhibit translation in E. coli due to activation of the stringent response (57). However, due to the absence of (p)ppGpp regulation in the $E$. coli $\mathrm{K} 1508$ strain used in this work (i.e., spoT and relA mutant), translation control based on $\mathrm{Mg}^{2+}$ levels is possibly absent, which would lead to the unchecked upregulation of ribosome assembly even during $\mathrm{Mg}^{2+}$ deficiency, a phenomenon which has been demonstrated in Salmonella (57).

Our transcriptome analyses showed that FZ and DOC upregulated efflux pump genes ( $a c r A, a c r B)$, downregulated porin genes (ompC, ompF) (Fig. 2F), and induced stress responses that are expected to increase the tolerance to these agents. In this context, it seems contradictory that the combination is synergistic rather than antagonistic. A possible explanation for observed synergy is that some of these resistance mechanisms are somehow being inhibited by the combined action of FZ, VAN, and DOC. A proposed pathway for inhibition of these resistance mechanisms could be through Fur inactivation or downregulation of the central carbon metabolism. Both of these activities will have an inhibitory effect on the $\operatorname{ETC}(25,58)$. FZ, DOC, and FVD downregulated the aerobic ETC genes nuo and cyd, which encode two of the primary ETC complexes, NADH dehydrogenase I and cytochrome $b d-\mathrm{I}$, that generate the proton motive force (PMF). These findings, along with the demonstrated overall decrease in aerobic respiration, could indicate diminished proton motive force in response to FZ and DOC. Since PMF is directly or indirectly required for the function of efflux pumps, low PMF is conducive for the accumulation of the antibacterials inside the cells by preventing efflux. These findings support our previous study in which deletion of tolC or acrA efflux pump genes resulted in the loss or reduction of synergy between FZ and DOC, highlighting the importance of efflux in the synergy mechanism (7).

VAN treatment of $E$. coli did not induce much change in overall gene expression compared to the control. Even though only 17 genes were significantly differentially expressed, these genes do, however, give insight into the initial cellular effects of VAN. The majority of the 17 DEGs are members of envelope stress responses, particularly the Rcs pathway, which has been demonstrated to be induced by peptidoglycan-targeting antibiotics (40). Taken together, these findings indicate that VAN on its own can somehow cross the outer membrane of $E$. coli, although only in minimal amounts, and inhibit peptidoglycan synthesis. From the known mechanisms of action of VAN (peptidoglycan synthesis inhibitor) and nitrofurans (DNA damage), there does not seem to be an obvious connection to why these drugs interact synergistically (8). One important mechanism of resistance to nitrofurans is the SOS response to DNA damage. Deletion of recA, making $E$. coli unable to mount an SOS response, resulted in the loss of synergy between FZ and VAN. Data presented here indicate the SOS response's involvement in the mechanism of synergy between FZ and VAN, possibly through inhibition of SOS induction by VAN, which can decrease the resistance to FZ's DNA-damaging effect and therefore increase lethality. The recA deletion also increased the $\mathrm{FICl}$ for the triple combination, but the interaction is still synergistic, supporting the concept of multiple interaction points that contribute to the synergy of FVD.

This study searched for the possible mechanistic bases of the synergy between FZ, DOC, and VAN using transcriptomics and biochemical approaches. The transcriptional responses shed light on the modes of action of FZ and DOC. By analyzing their highly similar perturbed pathways, in combination with VAN effects, it was possible to propose mechanisms for the synergy based on identified changes in gene expression. Particularly, we propose that the combined effects on the Fur pathway lead to (i) an increased labile iron pool that can cause oxidative damage to proteins and DNA and (ii) inhibition of ETC that can diminish PMF and subsequently inhibit PMF-dependent efflux activity. FZ and DOC's combined translational stress and VAN's possible inhibition of the SOS response, which can amplify the DNA damage, are also possible sources of synergy. FZ, DOC, and VAN affected correlated pathways that likely result in 
the suppression of resistance mechanisms and amplification of damaging effects. Although further work is warranted to fully elucidate these mechanisms, this study lays the groundwork for the development of this combination into a viable clinical therapy for tackling multidrug-resistant bacterial infections.

\section{MATERIALS AND METHODS}

Bacterial strain, growth conditions, and checkerboard assay. E. coli K1508 (MC4100 $\left[F^{-}\right.$araD $\Delta$ lac U169 relA1 spoT1 thiA rpsL (Str')] $\Delta$ lamB106) (20) was grown aerobically in 2 XYT medium at $37^{\circ} \mathrm{C}$. The Kan recA deletion mutation from the Keio collection (59) was introduced into E. coli K1508 using phage P1 transduction, as previously described (60). To eliminate potential polar effects on downstream genes in the operon, the FLP recombinase recognition target (FRT)-flanked $\mathrm{Kan}^{r}$ cassette was excised using FLP-mediated recombination using plasmid pCP20 (61).

Determination of MIC and checkerboard assay. MIC determinations and checkerboard assays were performed using the broth microdilution method in a 384-well plate according to the CLSI guidelines (62), with minor changes. 2XYT medium was used, the inoculum concentration was $1 \times 10^{6} \mathrm{CFU} /$ $\mathrm{ml}$, the plates were incubated at $37^{\circ} \mathrm{C}$ for $24 \mathrm{~h}$, and all experiments were performed in triplicate. MIC is the lowest concentration that completely inhibits growth.

Synergistic, antagonistic, and no interactions were determined using the fractional inhibitory concentration index (FICl) method, using the equation

$$
\mathrm{FICI}=\frac{\mathrm{MIC}_{\mathrm{FZ}(\mathrm{com})}}{\mathrm{MIC}_{\mathrm{FZ}}}+\frac{\mathrm{MIC}_{\mathrm{DOC}(\mathrm{com})}}{\mathrm{MIC}_{\mathrm{DOC}}}+\frac{\mathrm{MIC}_{\mathrm{VAN}(\mathrm{com})}}{\mathrm{MIC}_{\mathrm{VAN}}}
$$

where $\mathrm{MIC}_{\mathrm{FZ}(\mathrm{com}),} \mathrm{MIC}_{\mathrm{DOC}(\mathrm{com}) \text {, }}$ and $\mathrm{MIC}_{\mathrm{VAN}(\mathrm{com})}$ are the MIC of $\mathrm{FZ}$, DOC, or VAN, respectively, when used in combination and $\mathrm{MIC}_{\mathrm{FZ}}, \mathrm{MIC}_{\mathrm{DOC}}$, and $\mathrm{MIC}_{\mathrm{VAN}}$ are the MIC when used alone. Using the lowest $\mathrm{FICl}$, the interactions were interpreted as synergistic if $\mathrm{FICl}$ was $\leq 0.5$, indifferent if $\mathrm{FICl}$ was $>0.5$ to $\leq 4.0$, and antagonistic if $\mathrm{FICl}$ was $>4.0$ (63).

Total RNA isolation and sequencing. The concentrations that gave $50 \%$ growth inhibition $\left(\mathrm{IC}_{50}\right)$ at $24 \mathrm{~h}$ were chosen for the transcriptomics study. The $\mathrm{IC}_{50}$ determination was performed in 384-well plates on E. coli $\mathrm{K} 1508$ at $1 \times 10^{6} \mathrm{CFU} / \mathrm{ml}$ in a total volume of $50 \mu \mathrm{l}$. The plate was incubated at $37^{\circ} \mathrm{C}$ for $24 \mathrm{~h}$, and optical density at $600 \mathrm{~nm}\left(\mathrm{OD}_{600}\right)$ was determined. The mean percent growth inhibition was calculated, and the R package drc v3.0-1 (64) was used to plot the concentration-response (percent inhibition) curves fitted with a four-parameter log-logistic model to determine the $\mathrm{IC}_{50}$. For the combination, the most synergistic combination (i.e., lowest FICI) in a checkerboard assay was first determined (see Fig. S2 in the supplemental material), and then fixed-ratio dilutions of these concentrations were used to plot a concentration-response curve. The $\mathrm{IC}_{50} \mathrm{~s}$ for each antibacterial and combination, which were used in all the assays, are summarized in Table S1.

Exponentially growing cultures of E. coli K1508 at $5 \times 10^{7} \mathrm{CFU} / \mathrm{ml}$ were treated with the $\mathrm{IC}_{50}$ of the antibacterial(s) in a final volume of $25 \mathrm{ml}$. The dimethyl sulfoxide (DMSO) concentration for all treatments was fixed at $0.1 \%$. After incubation at $37^{\circ} \mathrm{C}$ with shaking at $200 \mathrm{rpm}$ for $1 \mathrm{~h}$, the cultures were harvested by centrifugation. The resulting pellet was then resuspended in $1 \mathrm{ml}$ of resuspension buffer ( $20 \mathrm{mM}$ sodium acetate, $\mathrm{pH} 5.5,1 \mathrm{mM}$ EDTA, 1\% SDS) and homogenized by bead beating. The samples were then subjected to phenol-chloroform nucleic acid extraction, as previously described (65), except that acid phenol with $\mathrm{pH} 4.45$ was used to extract RNA.

Experiments were conducted in quadruplicate, and the samples were sent to Novogene Co., Ltd. (Beijing, China), for rRNA depletion using a Ribo-Zero rRNA removal kit (Illumina), library preparation using the NEBNext Ultra Directional library prep kit for Illumina (New England Biolabs, USA), and subsequent 150 -bp paired-end RNA sequencing on a HiSeq 2500 sequencer (Illumina).

RNA-Seq analysis. Before analyzing the data, the quality of the reads was checked using FastQC v0.11.7-5 (66). The RNA sequencing reads were then mapped against the E. coli K1508 genome (NCBI GenBank accession no. CP072054) using HISAT2 v2.1.0 (67), and the number of reads that mapped to a gene was counted using featureCounts v1.6.0 (68) (Table S2).

Differential expression analysis was carried out using DESeq2 v1.26.0 (69). To better represent effect size (gene expression), $\log _{2} \mathrm{FC}$ estimates were shrunk using the apeglm v1.8.0 shrinkage estimator (70). Differentially expressed genes (DEGs) were defined as genes with an adjusted (adj) $P$ value (multiple test adjustment using the Benjamini-Hochberg method) of less than 0.01 (adj $P<0.01$ ) and fold changes greater than $1.5\left(\left|\log _{2} \mathrm{FC}\right|>0.58\right)$. The DEGs were clustered using k-means clustering of regularized logtransformed normalized counts into optimal $\mathrm{k}$ number of clusters identified by the mclust function of the R package mclust v5.4.6 (71). Gene Ontology (GO) term enrichment of the DEGs was performed using statistical overrepresentation test (Fisher's exact test with Benjamini-Hochberg false-discovery rate [FDR] multiple-test correction) in PANTHER v15.0 (72). The significantly overrepresented GO terms were selected using an FDR cutoff of 0.05 .

Mutagenicity assay. Mutation frequencies were measured as described previously (73). Briefly, exponentially growing E. coli K1508 at $1 \times 10^{7} \mathrm{CFU} / \mathrm{ml}$ was treated with $\mathrm{IC}_{50} \mathrm{~s}$ of $\mathrm{FZ}$, VAN, and DOC, alone and in combination, in a final volume of $10 \mathrm{ml}$ in $2 \times Y T$ medium. The cultures were incubated at $37^{\circ} \mathrm{C}$ with shaking at $200 \mathrm{rpm}$ for $24 \mathrm{~h}$. The cultures were then centrifuged at 5,000 $\times g$ for $10 \mathrm{~min}$ and resuspended in maximum recovery diluent $(0.1 \%$ peptone, $0.85 \% \mathrm{NaCl})$. Serial dilutions were plated in triplicate onto 2xYT agar containing $100 \mu \mathrm{g} / \mathrm{ml}$ rifampin to select for rifampin-resistant colonies and on nonselective $2 \times Y T$ agar to count the total number of colonies. The plates were scored after $24 \mathrm{~h}$ at $37^{\circ} \mathrm{C}$. The 
mutation frequency was calculated by dividing the number of rifampin-positive colonies by the total number of colonies from 9 to 11 biological replicates.

Oxygen consumption. Oxygen consumption was measured as previously described (74). Briefly, an E. coli $\mathrm{K} 1508$ culture at an $\mathrm{OD}_{600}$ of 0.3 was treated with $\mathrm{IC}_{50} \mathrm{~s}$ of $\mathrm{FZ}, \mathrm{VAN}$, and DOC, alone and in combination, at $37^{\circ} \mathrm{C}$ for $1 \mathrm{~h}$. Cells were then diluted in air-saturated $2 \mathrm{XYT}$ to an $\mathrm{OD}_{600}$ of 0.2 , and dissolved oxygen was measured in a closed chamber with constant stirring using a Clark-type oxygen electrode (Rank Brothers Ltd.) linked to a chart recorder (Vernier LabQuest Mini).

Metal concentration by ICP-MS. Antibiotic-treated E. coli cultures in a total volume of $80 \mathrm{ml}$ were processed the same way as for the transcriptomics analyses. After antibiotic treatment, cells were collected and prepared for ICP-MS, as previously described (75). Briefly, cells were harvested by centrifugation $(5,000 \times g, 10 \mathrm{~min})$ and then washed twice with $25 \mathrm{ml}$ phosphate-buffered saline (PBS) containing $0.5 \mathrm{mM}$ EDTA and then twice with PBS. All samples were adjusted to a cell number of $2 \times 10^{9} \mathrm{CFU}$ based on their $\mathrm{OD}_{600}$ values. Washed cell pellets were then digested with $500 \mu \mathrm{l}$ of $70 \%$ (wt/vol) nitric acid $\left(\geq 99.999 \%\right.$ trace metals basis) at $80^{\circ} \mathrm{C}$ overnight. Each sample was diluted 1:20 in Milli-Q water $(18.2$ $M \Omega)$, giving a final acid matrix of $3.5 \%$. The samples were then sent to the University of Waikato Mass Spectrometry Facility to analyze metal content by ICP-MS on an Agilent 8900 system.

Data availability. The transcriptomic raw data were deposited in GenBank under BioProject accession no. PRJNA642878.

\section{SUPPLEMENTAL MATERIAL}

Supplemental material is available online only.

FIG S1, PDF file, 0.6 MB.

FIG S2, PDF file, $0.2 \mathrm{MB}$.

FIG S3, PDF file, 0.2 MB.

TABLE S1, PDF file, $0.1 \mathrm{MB}$.

TABLE S2, PDF file, $0.1 \mathrm{MB}$.

DATA SET S1, XLSX file, 1.4 MB.

DATA SET S2, XLSX file, $0.2 \mathrm{MB}$.

DATA SET S3, XLSX file, $0.1 \mathrm{MB}$.

\section{ACKNOWLEDGMENTS}

We are grateful to Van Hung Vuong Le for sequencing the genome of E. coli K1508, to Adrian Koolaard for technical help with the oxygen electrode, and to Amanda French of the University of Waikato for carrying out the ICP-MS analysis.

This work was supported by a Massey University-MBIE PSAF II grant MU001985 and a generous donation by Anne and Bryce Carmine. We are indebted to Bryce and Anne Carmine for their generous donation that made this work possible. C.O. was supported by a Massey University PhD Scholarship. Funding from the College of Sciences MURF (covering publication fees) and School of Fundamental Sciences is gratefully acknowledged.

\section{REFERENCES}

1. World Health Organization. 2017. Antibacterial agents in clinical development: an analysis of the bacterial clinical development pipeline including tuberculosis. World Health Organization, Geneva, Switzerland. https:// apps.who.int/iris/handle/10665/258965.

2. Coates ARM, Hu Y, Holt J, Yeh P. 2020. Antibiotic combination therapy against resistant bacterial infections: synergy, rejuvenation and resistance reduction. Expert Rev Anti Infect Ther 18:5-15. https://doi.org/10.1080/14787210.2020.1705155.

3. Bollenbach T. 2015. Antimicrobial interactions: mechanisms and implications for drug discovery and resistance evolution. Curr Opin Microbiol 27: 1-9. https://doi.org/10.1016/j.mib.2015.05.008.

4. Xu X, Xu L, Yuan G, Wang Y, Qu Y, Zhou M. 2018. Synergistic combination of two antimicrobial agents closing each other's mutant selection windows to prevent antimicrobial resistance. Sci Rep 8:7237. https://doi.org/ 10.1038/s41598-018-25714-z.

5. Farha MA, Brown ED. 2019. Drug repurposing for antimicrobial discovery. Nat Microbiol 4:565-577. https://doi.org/10.1038/s41564-019-0357-1.

6. Olivera C, Le VVH, Davenport C, Rakonjac J. 2021. In vitro synergy of 5nitrofurans, vancomycin and sodium deoxycholate against Gram-negative pathogens. J Med Microbiol 70:001304. https://doi.org/10.1099/jmm .0 .001304 .

7. Le V, Olivera C, Spagnuolo J, Davies I, Rakonjac J. 2020. In vitro synergy between sodium deoxycholate and furazolidone against enterobacteria. BMC Microbiol 20:5. https://doi.org/10.1186/s12866-019-1668-3.
8. Zhou A, Kang TM, Yuan J, Beppler C, Nguyen C, Mao Z, Nguyen MQ, Yeh P, Miller JH. 2015. Synergistic interactions of vancomycin with different antibiotics against Escherichia coli: trimethoprim and nitrofurantoin display strong synergies with vancomycin against wild-type $E$. coli. Antimicrob Agents Chemother 59:276-281. https://doi.org/10.1128/AAC.03502-14.

9. World Health Organization. 2017. Prioritization of pathogens to guide discovery, research and development of new antibiotics for drug-resistant bacterial infections, including tuberculosis. World Health Organization, Geneva, Switzerland. https://apps.who.int/iris/handle/10665/311820.

10. Whiteway J, Koziarz P, Veall J, Sandhu N, Kumar P, Hoecher B, Lambert IB. 1998. Oxygen-insensitive nitroreductases: analysis of the roles of $n f s A$ and $n f s B$ in development of resistance to 5-nitrofuran derivatives in Escherichia coli. J Bacteriol 180:5529-5539. https://doi.org/10.1128/JB.180.21 .5529-5539.1998.

11. Ona KR, Courcelle CT, Courcelle J. 2009. Nucleotide excision repair is a predominant mechanism for processing nitrofurazone-induced DNA damage in Escherichia coli. J Bacteriol 191:4959-4965. https://doi.org/10 .1128/JB.00495-09.

12. Obaseiki-Ebor EE, Akerele JO. 1986. Nitrofuran mutagenicity: induction of frameshift mutations. Mutat Res Lett 175:149-152. https://doi.org/10 .1016/0165-7992(86)90114-4.

13. McOsker CC, Fitzpatrick PM. 1994. Nitrofurantoin: mechanism of action and implications for resistance development in common uropathogens. J 
Antimicrob Chemother 33(Suppl A):23-30. https://doi.org/10.1093/jac/33 suppl_a.23.

14. Tu Y, McCalla DR. 1976. Effect of nitrofurazone on bacterial RNA and ribosome synthesis and on the function of ribosomes. Chem Biol Interact 14: 81-91. https://doi.org/10.1016/0009-2797(76)90026-0.

15. Begley M, Gahan CGM, Hill C. 2005. The interaction between bacteria and bile. FEMS Microbiol Rev 29:625-651. https://doi.org/10.1016/j.femsre 2004.09.003.

16. Cremers CM, Knoefler D, Vitvitsky V, Banerjee R, Jakob U. 2014. Bile salts act as effective protein-unfolding agents and instigators of disulfide stress in vivo. Proc Natl Acad Sci U S A 111:E1610-E1619. https://doi.org/ 10.1073/pnas.1401941111.

17. Merritt ME, Donaldson JR. 2009. Effect of bile salts on the DNA and membrane integrity of enteric bacteria. J Med Microbiol 58:1533-1541. https:// doi.org/10.1099/jmm.0.014092-0.

18. Reynolds PE. 1989. Structure, biochemistry and mechanism of action of glycopeptide antibiotics. Eur J Clin Microbiol Infect Dis 8:943-950. https://doi.org/10.1007/BF01967563.

19. Stokes JM, French S, Ovchinnikova OG, Bouwman C, Whitfield C, Brown ED. 2016. Cold stress makes Escherichia coli susceptible to glycopeptide antibiotics by altering outer membrane integrity. Cell Chem Biol 23: 267-277. https://doi.org/10.1016/j.chembiol.2015.12.011.

20. Spagnuolo J, Opalka N, Wen WX, Gagic D, Chabaud E, Bellini P, Bennett MD, Norris GE, Darst SA, Russel M, Rakonjac J. 2010. Identification of the gate regions in the primary structure of the secretin pIV. Mol Microbiol 76:133-150. https://doi.org/10.1111/j.1365-2958.2010.07085.x.

21. Nikaido H. 2003. Molecular basis of bacterial outer membrane permeability revisited. Microbiol Mol Biol Rev 67:593-656. https://doi.org/10.1128/ MMBR.67.4.593-656.2003.

22. Thanassi DG, Cheng LW, Nikaido H. 1997. Active efflux of bile salts by Escherichia coli. J Bacteriol 179:2512-2518. https://doi.org/10.1128/jb.179 8.2512-2518.1997.

23. Quillardet $P$, Arrault X, Michel V, Touati E. 2006. Organ-targeted mutagenicity of nitrofurantoin in Big Blue transgenic mice. Mutagenesis 21: 305-311. https://doi.org/10.1093/mutage/gel036.

24. Kari FW, Huff JE, Leininger J, Haseman JK, Eustis SL. 1989. Toxicity and carcinogenicity of nitrofurazone in $\mathrm{F} 344 / \mathrm{N}$ rats and B6C3F1 mice. Food Chem Toxicol 27:129-137. https://doi.org/10.1016/0278-6915(89)90008-2.

25. McHugh JP, Rodríguez-Quinoñes $F$, Abdul-Tehrani $H$, Svistunenko DA, Poole RK, Cooper CE, Andrews SC. 2003. Global iron-dependent gene regulation in Escherichia coli: a new mechanism for iron homeostasis. J Biol Chem 278:29478-29486. https://doi.org/10.1074/jbc.M303381200.

26. Nandal A, Huggins CC, Woodhall MR, McHugh J, Rodríguez-Quiñones $F$, Quail MA, Guest JR, Andrews SC. 2010. Induction of the ferritin gene (ftnA) of Escherichia coli by $\mathrm{Fe}^{2+}-\mathrm{Fur}$ is mediated by reversal of $\mathrm{H}-\mathrm{NS}$ silencing and is RyhB independent. Mol Microbiol 75:637-657. https://doi .org/10.1111/j.1365-2958.2009.06977.x.

27. Massé $E$, Gottesman S. 2002. A small RNA regulates the expression of genes involved in iron metabolism in Escherichia coli. Proc Natl Acad Sci U S A 99:4620-4625. https://doi.org/10.1073/pnas.032066599.

28. Massé E, Vanderpool CK, Gottesman S. 2005. Effect of RyhB small RNA on global iron use in Escherichia coli. J Bacteriol 187:6962-6971. https://doi .org/10.1128/JB.187.20.6962-6971.2005.

29. Seo SW, Kim D, Latif H, O'Brien EJ, Szubin R, Palsson BO. 2014. Deciphering Fur transcriptional regulatory network highlights its complex role beyond iron metabolism in Escherichia coli. Nat Commun 5:4910. https:// doi.org/10.1038/ncomms5910.

30. Wehrli W. 1983. Rifampin: mechanisms of action and resistance. Rev Infect Dis 5(Suppl 3):S407-S411. https://doi.org/10.1093/clinids/5.supplement 3.s407.

31. Ingledew WJ, Poole RK. 1984. The respiratory chains of Escherichia coli. Microbiol Rev 48:222-271. https://doi.org/10.1128/mr.48.3.222-271.1984.

32. Chandrangsu P, Rensing C, Helmann JD. 2017. Metal homeostasis and resistance in bacteria. Nat Rev Microbiol 15:338-350. https://doi.org/10 .1038/nrmicro.2017.15.

33. Tan G, Cheng Z, Pang Y, Landry AP, Li J, Lu J, Ding H. 2014. Copper binding in IscA inhibits iron-sulphur cluster assembly in Escherichia coli. Mol Microbiol 93:629-644. https://doi.org/10.1111/mmi.12676.

34. Macomber L, Imlay JA. 2009. The iron-sulfur clusters of dehydratases are primary intracellular targets of copper toxicity. Proc Natl Acad Sci U S A 106:8344-8349. https://doi.org/10.1073/pnas.0812808106.

35. Chillappagari S, Seubert A, Trip H, Kuipers OP, Marahiel MA, Miethke M. 2010. Copper stress affects iron homeostasis by destabilizing iron-sulfur cluster formation in Bacillus subtilis. J Bacteriol 192:2512-2524. https://doi .org/10.1128/JB.00058-10.

36. Steunou AS, Bourbon M-L, Babot M, Durand A, Liotenberg S, Yamaichi $Y$ Ouchane S. 2020. Increasing the copper sensitivity of microorganisms by restricting iron supply, a strategy for bio-management practices. Microb Biotechnol 13:1530-1545. https://doi.org/10.1111/1751-7915.13590.

37. Anjem A, Varghese S, Imlay JA. 2009. Manganese import is a key element of the OxyR response to hydrogen peroxide in Escherichia coli. Mol Microbiol 72:844-858. https://doi.org/10.1111/j.1365-2958.2009.06699.x.

38. Kehres DG, Janakiraman A, Slauch JM, Maguire ME. 2002. Regulation of Salmonella enterica serovar Typhimurium mntH transcription by $\mathrm{H}_{2} \mathrm{O}_{2}$ $\mathrm{Fe}^{2+}$, and $\mathrm{Mn}^{2+}$. J Bacteriol 184:3151-3158. https://doi.org/10.1128/JB .184.12.3151-3158.2002.

39. Zheng M, Wang X, Templeton LJ, Smulski DR, LaRossa RA, Storz G. 2001. DNA microarray-mediated transcriptional profiling of the Escherichia coli response to hydrogen peroxide. J Bacteriol 183:4562-4570. https://doi .org/10.1128/JB.183.15.4562-4570.2001.

40. Laubacher ME, Ades SE. 2008. The Rcs phosphorelay is a cell envelope stress response activated by peptidoglycan stress and contributes to intrinsic antibiotic resistance. J Bacteriol 190:2065-2074. https://doi.org/ 10.1128/JB.01740-07.

41. Kamenšek S, Žgur-Bertok D. 2013. Global transcriptional responses to the bacteriocin colicin M in Escherichia coli. BMC Microbiol 13:42. https://doi .org/10.1186/1471-2180-13-42.

42. Hammes WP, Neuhaus FC. 1974. On the mechanism of action of vancomycin: inhibition of peptidoglycan synthesis in Gaffkya homari. Antimicrob Agents Chemother 6:722-728. https://doi.org/10.1128/AAC.6.6.722.

43. O'Rourke A, Beyhan S, Choi Y, Morales P, Chan AP, Espinoza JL, Dupont CL, Meyer KJ, Spoering A, Lewis K, Nierman WC, Nelson KE. 2020. Mechanism-of-action classification of antibiotics by global transcriptome profiling. Antimicrob Agents Chemother 64:e01207-19. https://doi.org/10 .1128/AAC.01207-19.

44. Witkin EM. 1991. RecA protein in the SOS response: milestones and mysteries. Biochimie 73:133-141. https://doi.org/10.1016/0300-9084(91)90196-8.

45. Bansal M, Yang J, Karan C, Menden MP, Costello JC, Tang H, Xiao G, Li Y, Allen J, Zhong R, Chen B, Kim M, Wang T, Heiser LM, Realubit R, Mattioli M, Alvarez MJ, Shen Y, Gallahan D, Singer D, Saez-Rodriguez J, Xie Y, Stolovitzky G, Califano A, NCI-DREAM Community. 2014. A community computational challenge to predict the activity of pairs of compounds. Nat Biotechnol 32:1213-1222. https://doi.org/10.1038/nbt.3052.

46. Yang M, Jaaks P, Dry J, Garnett M, Menden MP, Saez-Rodriguez J. 2020. Stratification and prediction of drug synergy based on target functional similarity. NPJ Syst Biol Appl 6:16. https://doi.org/10.1038/s41540-020 -0136-x.

47. Hamner S, McInnerney K, Williamson K, Franklin MJ, Ford TE. 2013. Bile salts affect expression of Escherichia coli 0157:H7 genes for virulence and iron acquisition, and promote growth under iron limiting conditions. PLoS One 8:e74647. https://doi.org/10.1371/journal.pone.0074647.

48. Fu H, Leng W, Wang J, Zhang W, Peng J, Wang L, Jin Q. 2007. Transcriptional profile induced by furazolidone treatment of Shigella flexneri. Appl Microbiol Biotechnol 77:657-667. https://doi.org/10.1007/s00253-007 -1180-9.

49. Jacobs A, Miles PM. 1970. The formation of iron complexes with bile and bile constituents. Gut 11:732-734. https://doi.org/10.1136/gut.11.9.732.

50. Varghese S, Wu A, Park S, Imlay KRC, Imlay JA. 2007. Submicromolar hydrogen peroxide disrupts the ability of Fur protein to control free-iron levels in Escherichia coli. Mol Microbiol 64:822-830. https://doi.org/10 $.1111 / j .1365-2958.2007 .05701 . x$.

51. Imlay JA. 2006. Iron-sulphur clusters and the problem with oxygen. Mol Microbiol 59:1073-1082. https://doi.org/10.1111/j.1365-2958.2006.05028.x.

52. D'Autreaux B, Touati D, Bersch B, Latour J-M, Michaud-Soret I. 2002. Direct inhibition by nitric oxide of the transcriptional ferric uptake regulation protein via nitrosylation of the iron. Proc Natl Acad Sci U S A 99:16619-16624. https://doi.org/10.1073/pnas.252591299.

53. Kumar M, Adhikari S, Hurdle JG. 2014. Action of nitroheterocyclic drugs against Clostridium difficile. Int J Antimicrob Agents 44:314-319. https:// doi.org/10.1016/j.ijantimicag.2014.05.021.

54. Keyer K, Imlay JA. 1996. Superoxide accelerates DNA damage by elevating free-iron levels. Proc Natl Acad Sci U S A 93:13635-13640. https://doi.org/ 10.1073/pnas.93.24.13635.

55. Sabina J, Dover N, Templeton LJ, Smulski DR, Söll D, LaRossa RA. 2003. Interfering with different steps of protein synthesis explored by transcriptional profiling of Escherichia coli K-12. J Bacteriol 185:6158-6170. https:// doi.org/10.1128/JB.185.20.6158-6170.2003. 
56. Lin X, Kang L, Li H, Peng X. 2014. Fluctuation of multiple metabolic pathways is required for Escherichia coli in response to chlortetracycline stress. Mol Biosyst 10:901-908. https://doi.org/10.1039/c3mb70522f.

57. Pontes $\mathrm{MH}$, Yeom J, Groisman EA. 2016. Reducing ribosome biosynthesis promotes translation during low $\mathrm{Mg}^{2+}$ stress. Mol Cell 64:480-492. https:// doi.org/10.1016/j.molcel.2016.05.008.

58. Koebmann BJ, Westerhoff HV, Snoep JL, Nilsson D, Jensen PR. 2002. The glycolytic flux in Escherichia coli is controlled by the demand for ATP. J Bacteriol 184:3909-3916. https://doi.org/10.1128/JB.184.14.3909-3916 .2002.

59. Baba T, Ara T, Hasegawa M, Takai Y, Okumura Y, Baba M, Datsenko KA, Tomita M, Wanner BL, Mori H. 2006. Construction of Escherichia coli K-12 in-frame, single-gene knockout mutants: the Keio collection. Mol Syst Biol 2:2006.0008. https://doi.org/10.1038/msb4100050.

60. Thomason LC, Costantino N, Court DL. 2007. E. coli genome manipulation by P1 transduction. Curr Protoc Mol Biol Chapter 1:Unit 1.17. https://doi .org/10.1002/0471142727.mb0117s79.

61. Cherepanov PP, Wackernagel W. 1995. Gene disruption in Escherichia coli: TcR and KmR cassettes with the option of Flp-catalyzed excision of the antibiotic-resistance determinant. Gene 158:9-14. https://doi.org/10 .1016/0378-1119(95)00193-A.

62. Clinical and Laboratory Standards Institute. 2015. Methods for dilution antimicrobial susceptibility tests for bacteria that grow aerobically, 10th ed. Clinical and Laboratory Standards Institute, Wayne, PA.

63. Odds FC. 2003. Synergy, antagonism, and what the chequerboard puts between them. J Antimicrob Chemother 52:1. https://doi.org/10.1093/ jac/dkg301.

64. Ritz C, Baty F, Streibig JC, Gerhard D. 2015. Dose-response analysis using R. PLoS One 10:e0146021. https://doi.org/10.1371/journal.pone.0146021.

65. Green MR, Sambrook J. 2017. Isolation of high-molecular-weight DNA using organic solvents. Cold Spring Harb Protoc 2017:pdb.prot093450. https://doi.org/10.1101/pdb.prot093450.

66. Andrews S. 2010. FastQC: a quality control tool for high throughput sequence data. http://www.bioinformatics.babraham.ac.uk/projects/fastqc. Accessed January 2019.
67. Kim D, Langmead B, Salzberg SL. 2015. HISAT: a fast spliced aligner with low memory requirements. Nat Methods 12:357-360. https://doi.org/10 .1038/nmeth.3317.

68. Liao Y, Smyth GK, Shi W. 2014. featureCounts: an efficient general purpose program for assigning sequence reads to genomic features. Bioinformatics 30:923-930. https://doi.org/10.1093/bioinformatics/btt656.

69. Love MI, Huber W, Anders S. 2014. Moderated estimation of fold change and dispersion for RNA-seq data with DESeq2. Genome Biol 15:550. https://doi.org/10.1186/s13059-014-0550-8.

70. Zhu A, Ibrahim JG, Love MI. 2019. Heavy-tailed prior distributions for sequence count data: removing the noise and preserving large differences. Bioinformatics 35:2084-2092. https://doi.org/10.1093/bioinformatics/bty895.

71. Scrucca L, Fop M, Murphy TB, Raftery AE. 2016. mclust 5: clustering, classification and density estimation using Gaussian finite mixture models. R J 8:289-317. https://doi.org/10.32614/RJ-2016-021.

72. Mi H, Muruganujan A, Ebert D, Huang X, Thomas PD. 2019. PANTHER version 14: more genomes, a new PANTHER GO-slim and improvements in enrichment analysis tools. Nucleic Acids Res 47:D419-D426. https://doi .org/10.1093/nar/gky1038.

73. Krisko A, Radman M. 2013. Phenotypic and genetic consequences of protein damage. PLoS Genet 9:e1003810. https://doi.org/10.1371/journal .pgen.1003810.

74. Liu Y, Imlay JA. 2013. Cell death from antibiotics without the involvement of reactive oxygen species. Science 339:1210-1213. https://doi.org/10 $.1126 /$ science. 1232751

75. Williams CL, Neu HM, Michel SLJ, Merrell DS. 2019. Measuring intracellular metal concentration via ICP-MS following copper exposure. Methods Mol Biol 1946:195-205. https://doi.org/10.1007/978-1-4939-9118-1_19.

76. Ferrières L, Clarke DJ. 2003. The RcsC sensor kinase is required for normal biofilm formation in Escherichia coli K-12 and controls the expression of a regulon in response to growth on a solid surface. Mol Microbiol 50: 1665-1682. https://doi.org/10.1046/j.1365-2958.2003.03815.x. 